\title{
Evaluating Ginkgo Leaf Necrosis and Asymmetric Crown Discolor- ation Induced by Typhoon 0613 with RGB Image Analysis
}

\author{
Fei WANG*, Haruhiko YAMAMOTO**, Yasuomi IBARAKI**, \\ Kiyoshi IWAYA**, and Naru TAKAYAMA** \\ $\left(\begin{array}{c}* \text { The United Graduate School of Agriculture Science, Tottori University } \\ * * \text { Faulty of Agriculture, Yamaguchi University }\end{array}\right)$
}

\begin{abstract}
As one kind of disaster, typhoons can cause serious damage to landscape trees both mechanically and physiologically. The Typhoon 0613 was characterized by strong wind associated with less rainfall when it passed through Yamaguchi City, Japan. After hit by it, the symptoms of leaf necrosis appeared on many ginkgo trees from coast to inland and the crowns of them became asymmetrically discolored. Due to the big body of ginkgo trees, this kind of phenomenon was often described by visual scale method characterized by significant deviation and observer specific. In order to quantitatively estimate the symptoms of damage, the leaf necrotic area percentage (LNAP), crown discoloration area percentage (CDAP) and inflection point (IP) of the threshold response function for asymmetric discolored crowns were determined by image pixel method. The green/luminance $(\mathrm{G} / \mathrm{L})$ value was measured by using the RGB images respectively scanned by a flat bed scanner from individual leaves and taken with a CCD digital camera from crowns. Significant relationship between $G / \mathrm{L}_{\text {leaf }}$ and LNAP, and between $\mathrm{G} / \mathrm{L}_{\text {crown }}$ and CDAP were obtained with the correlation coefficient of $\mathrm{R}^{2}=0.941$ and $\mathrm{R}^{2}=0.826$ separately. This suggested that both leaf necrosis and asymmetric crown discoloration of ginkgo trees induced by Typhoon 0613 can be quantitatively estimated by measuring the $\mathrm{G} / \mathrm{L}$ value from both leaves and crowns. The significant relation between CDAP and IP $\left(\mathrm{R}^{2}=0.811\right)$ reveals that both statistically calculated IP value and visually divided CDAP value can be used in estimating the asymmetric crown characters. The estimation of sampled leaves showed that it was the difference of necrotic leaves between windward and leeward made the crown of damaged ginkgo trees appear asymmetrical discoloration. Image threshold responsive analysis of ginkgo crowns hit by Typhoon 0613 indicated that the injury of ginkgo crowns was more serious on windward than leeward. The relationship between the distance from coastline (DC) and $\mathrm{G} / \mathrm{L}_{\text {crown }}$ value presented that the farther from the coastline, the bigger the $\mathrm{G} / \mathrm{L}_{\text {crown }}$ value of ginkgo crowns. Comparing to the sampling method, image analysis can be more effective being applied in field measurement of damaged status of ginkgo trees hit by severe typhoons for the reason of less labor and less time requirement. It may be an alternative tool to be used in estimating the degree of damage to ginkgo trees by typhoons like Typhoon 0613 .
\end{abstract}

Key words: Asymmetric crown discoloration, Ginkgo, Leaf necrosis, Logistic threshold responsive function, Typhoon 0613.

\section{Introduction}

Plants respond to unfavorably extreme environmental stresses in many different ways, which includes growth response, reproductive effect, abscission of

Received; March 24, 2008.

Accepted; October 7, 2008. organs, life form variation, chlorosis and necrosis etc. Necrosis is considered as death of the cells, tissues, organs, or the entire plant. As response to unfavorably extreme stresses, such as salt injury, drought, high/low temperature, nutrition deficiency and excessive pesticide, transplanting shock, root injury and diseases, many plants, including trees and shrubs, show symptoms necrosis at leaf tip and margin even on 
entire leaf (Treshow, 1970; Durbin, 1978; Vollenweider and Günthardt-Goerg, 2006; Günthardt-Goerg and Vollenweider, 2007). Ginkgo (Ginkgo biloba L.) is a showy ornamental tree species due to its special leaf morphology and golden yellow leaf color in fall. It is widely planted in China, Japan and to be a reasonable tree species for urban planting in Europe and America etc. (Santamour et al., 1983). Nevertheless, it sometimes appears leaf necrosis (Okinaka et al., 1990) and twig die back (Shimizu, 2004) after hit by strong typhoon or damaged by high temperature (Treshow, 1970), under abnormal meteorological event and in the unfavorable site condition (Tian and Jing, 2006), especially along the coast.

Typhoons are one kind of disaster that can cause seriously mechanical damage to forests, trees and shrubs, including uprooting, stem breaking, bending and leaning and so on (Takahashi and Tani, 1981; Yamamoto, 1979; Nobel, 1981; Maki et al., 1991). They are also complex calamities that can induce many unfavorable extreme or limit stresses like flooding, gusty wind and drought as well as salt/sand spray, which can lead plants into physiological injuries (Maki et al., 1991; Nobel, 1981). The Typhoon 0613 originated from the sea area east to the Philippines on Sep.9, 2006 and took the similar track as the catastrophic Typhoon 9119 and 0418. It hit the Japan Islands starting from the vicinity of Sasebo City, Nagasaki Prefecture and shaved the Yamaguchi Prefecture. Its max gusty wind speed reached $42.4 \mathrm{~m} / \mathrm{s}$ and minimum air pressure at sea level was $980.4 \mathrm{hPa}$ as well as less rainfall associated when it passed through the Yamaguchi City (Fig. 1). According to the data from Yamaguchi meteorological observatory, the precipitation was only $26 \mathrm{~mm}$ during the period hit by Typhoon 0613 and as the max wind speed reached to the peak almost no rainfall associated. Although seldom damage to the local people, constructions and roads occurred and there was no severely mechanical damage to trees in Yamaguchi city, it did lead to physiologically injury to many trees hit by Typhoon 0613. Tip and margin leaf necrosis appeared on many ginkgo trees in Yamaguchi after hit by it. It made the crown of ginkgo trees become asymmetrically discolored with the green and non-green parts clearly distinguishable.

To evaluate the degree and scope of typhoon damage, analyze the damage mechanism and automatically diagnose the typhoon damage, objectively and accurately measuring and analyzing the symptoms of

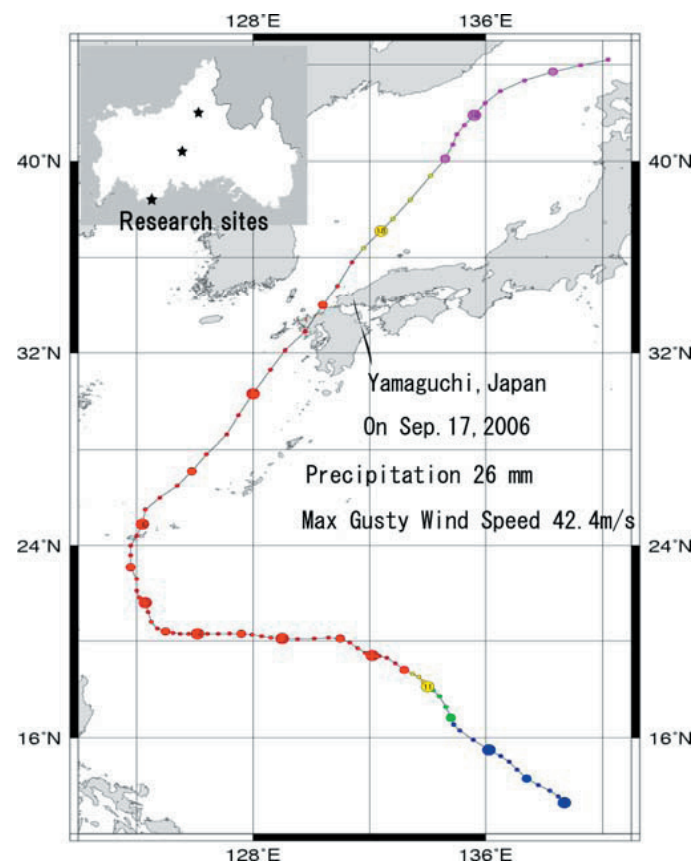

Fig. 1 Track of the Typhoon 0613. When it hit the Yamaguchi City on Sep. 17, 2006, the max gusty wind speed reached $42.4 \mathrm{~m} / \mathrm{s}$ and the precipitation was $26 \mathrm{~mm}$ during hit by Typhoon 0613. Almost no rainfall associated when the wind reached the maximum speed.

injured trees is necessary. As the main organ of trees, the crown is often used to evaluate the health status of them (Solberg, 1999; Rogers, 2002). But the less objective crown data made it difficult to establish the relationship to the visually estimated crown transparency in Europe wide investigations of forest health (Mizoue and Masutani, 2003). The big body of tree crown, compared to annual plants, and complex three-dimensional structure make them difficult to be measured. Although many previous studies on typhoon damage to landscape trees involved the ginkgo, the visual scale method was more common in observing the damage characters of ginkgo crowns (Okinaka et al., 1984, 1990). In comparison with sampling method, the digital image analysis is characterized by less labor and less time requirement (Karcher and Richardson, 2003; Richardson et al., 2001). Comparing to visual scale estimation, it is less affected by subjective judgement (Solberg, 1999) and reproducible (Richardson et al., 2001; Geneve et al., 2001) with lower observation deviation (Richardson et al., 2001). In contrast with 
other objective color analysis method, the RGB image analysis is low cost (Kawashima and Nakatani, 1998; Karcher and Richardson, 2003). As a nondestructive and noninvasive method, digital image analysis has ever been used to measure leaf area index and gap fraction of plant canopy (Bréda, 2003), crop coverage (Purcell, 2000), pest damage (Skaloudova et al., 2006) and tree crown transparency (Mizoue and Masutani, 2003) and so on.

The image analysis and concerned studies used in measuring plant chlorophyll, nitrogen and stress status have been much reported (Kawashima and Nakatani, 1998, Okado and Nakamura, 1993, Suzuki, et al. 1995). Suzuki et al. (1999) used the $\mathrm{G} /(\mathrm{R}+\mathrm{G}+\mathrm{B})$ for broccoli identification. Since the $G$ and $R$ values in the RGB color system were sensitive to the green and brown or red brown leaves, it was no surprise that the $G / R$ value is used in measuring the leaves and plant canopy. In the research of wheat senescence, Adamsen et al. (1999) held that the relationship between G/R and SPAD value (data read from SPAD-502 chlorophyll meter) was linear over most of the range of $G / R$ values. The $\mathrm{G} / \mathrm{R}$ value responded to both chlorophyll concentrations in leaves and leaf numbers. Although, the observation conditions, objective plant materials and selected optimal indices from different authors varied, the commonality of them included the utilization of RGB proportional values and color analysis of plant as well as on chlorophyll evaluation of the plant canopy (Cai et al., 2006). Seldom studies have been found on the leaf necrosis by RGB image analysis, especially on the leaf necrotic area and asymmetric crown discoloration induced by typhoons.

The light specific characters of photo images can affect the result of image analysis; even make it not easy to be in progress in clear daylight condition (Kawashima and Nakatani, 1998). The persistent anticyclone weather after Typhoon 0613's hit led to difficulty to find persistent and evenly scattered light conditions. Photo images taken during this period usually contained clear blue background. In order to improve the accuracy of image analysis, we had to search the proper color indices to reduce the light effect.

In the Lab color system $\mathrm{L}$ value stands for "luminance", which is a linear combination of the $R, G$ and $\mathrm{B}$ values (refer to formula 3 ) and increases with the enhanced brightness. Based on general mathematic principle, the $\mathrm{G} / \mathrm{L}$ will decrease with the $\mathrm{L}$ value increasing. It can be considered as an improved $\mathrm{G} /(\mathrm{R}+$ $\mathrm{G}+\mathrm{B}$ ) value fitting the bright environment. Iwaya and Yamamoto (2005) studied the relationship between the panicle water content of paddy rice with 19 color indices, in which the $\mathrm{G} / \mathrm{L}$ value was the highest one related to panicle water content of paddy rice in 1998 with $\mathrm{R}^{2}=0.919$. Whether or not it can be used in determining the ginkgo leaf necrosis and asymmetric crown discoloration is needed to make clear.

To study the symptoms of ginkgo damaged by Typhoon 0613 with a rapid, low cost, noninvasive and nondestructive method, image analysis was used in the study. By measuring the leaf necrotic area percentage (LNAP), crown discolored area percentage (CDAP) and the green/luminance $(\mathrm{G} / \mathrm{L})$ value for both leaves and crowns as well as the $\mathrm{G} / \mathrm{R}$ value for crowns, using the logistic threshold responsive analysis, the feasibility for describing damaged status of ginkgo trees hit by Typhoon 0613 was studied.

\section{Materials and Methods}

The RGB images were respectively obtained from both indoor image scanning from leaves and outdoor photo taking from crowns. For the image analysis of individual ginkgo leaves, six standard branches, three each from leeward and windward of the damaged crowns respectively, taken from three trees in a shelterbelt were sampled from Yamaguchi University. All leaves on the branches were visually divided and counted into five necrotic scales of nil, slight, middle, serious and dead. All of partial necrotic leaves and partial leaves of entirely green and overall brown, in total 153 leaves, were scanned with a flat bed scanner (Canon D125u2).

LNAP is the proportion of necrotic part to entire leaf area. It was measured by getting pixel numbers of entire leaf and the green part (refer to Fig. 2) with Photoshop. Before getting pixel data, the background except the objective leaf was manually removed by using eraser tool of Photoshop. The green part of the leaf was separated also by using magic eraser tool of Photoshop at default fault-tolerant status (32) or smaller if the non-green part was over-erased. The LNAP of individual leaves were calculated by formula (1).

$$
L N A P=\frac{100 \times(T T-G P)}{T T}
$$

Where, TT is the pixel numbers of overall leaf; GP is the pixel numbers of green part. 


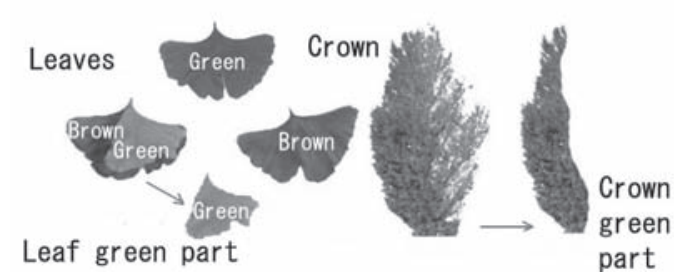

Fig. 2 Leaf necrosis and asymmetric crown discolortion of ginkgo tree induced by Typhoon 0613, and the green parts of both ginkgo leaf and crown

The $\mathrm{G} / \mathrm{L}_{\text {leaf }}$ value was measured by following process with same images prepared in calculation of LNAP. The image background was selected with Magic Wand Tool (A selection tool which can select the pixels with similar RGB values) of Photoshop and the leaf was extracted by inverse selection. The green $(\mathrm{G})$ and luminance (L) values of leaves were read from the average histogram value. The $\mathrm{G} / \mathrm{L}_{\text {leaf }}$ is the proportion of green value to luminance value from the RGB image of individual leaf. It was calculated by formula (2).

$$
G / L_{\text {leaf }}=\frac{\text { Green value of leaf }}{\text { Luminance value of leaf }}
$$

In which, the $\mathrm{L}$ value is a linear combination of $\mathrm{R}$, $\mathrm{G}$ and $\mathrm{B}$ values shown in formula (3).

$$
L=0.299 R+0.587 G+0.114 B
$$

The sites for researching asymmetric discolored crowns of ginkgo were located in the area from $131^{\circ} 16^{\prime}$ to $131^{\circ} 45^{\prime}$ east longitude and from $33^{\circ} 55^{\prime}$ to $34^{\circ} 25^{\prime}$ north latitude. The photo image of ginkgo trees was taken in a long, narrow area near the Yamaguchi Bay, Fushino River and Anno River in Yamaguchi City (refer to Fig. 1). The sampled ginkgo trees did not include newly planted trees, newly pruned trees and the trees sheltered by houses, buildings and other trees and so on. Most of them were selected in open sites and almost all the data used in result analysis were relative values from the same leaf or crown.

The RGB images for calculation of the CDAP and $\mathrm{G} / \mathrm{L}_{\text {crown }}$ values were taken with a $\mathrm{CCD}$ digital camera (Canon IXY 6.0). The camera was set to auto white balance, auto ISO sensitivity and the image resolution was $1200 \times 1600$ pixels with images stored in the files of JPEG form. It was the vertical profile of sampled tree taken on ground with little elevations 45 days after Typhoon 0613's hit under natural day light condition
(From 900JST to 1600 JST). The distance of photo taking was determined by fitting the crown to the screen of camera. The position of photo taking was fixed by turning around the sampled tree till the crown can be clearly divided into green part and non-green part so that we can capture the exact sideward (A profile of crown perpendicular to leeward or windward) image. The absolute geographical position of sampled trees was fixed by GPS with Caplio 500SE Ricoh camera.

Firstly, the images were prepared and the part except sampled crown was removed from the image with eraser tool of Photoshop. The removing process was showed in Fig. 3. After selected the crown with Magic Wand Tool of Photoshop, the G and L values were also read from the average histogram of Photoshop. The $\mathrm{G} / \mathrm{L}_{\text {crown }}$ value is the proportion of green to luminance value of crown. It was calculated by formula (4). The $G / R_{\text {crown }}$ value was obtained with same image and method, and similarly calculated by formula (5) for comparison with the $\mathrm{G} / \mathrm{L}_{\text {crown. }}$

$$
G / L_{\text {crown }}=\frac{\text { green value of the crown }}{\text { Luminance value of the crown }}
$$

$$
G / R_{\text {crown }}=\frac{\text { green value of the crown }}{\text { red value of the crown }}
$$

The CDAP, considered as the criterion status of damaged crowns hit by Typhoon 0613, is the pixel proportion of non-green part to entire profile of the crown. During measurement, the green part of the crown (refer to Fig. 2) was visually extracted by

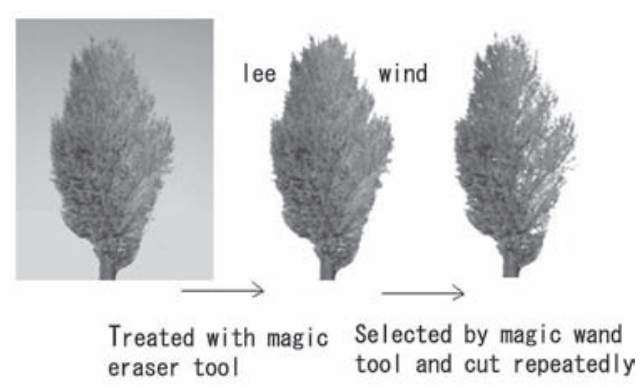

Fig. 3 Extracting process of ginkgo crown with Photoshop software. Firstly the background was removed by eraser tool, then selected the background interweaving with the crown and cut it out. This process approached repeatedly until the part out of crown was thoroughly removed. 
transitional color. After getting the pixel numbers of the entire crown and green part, the CDAP was calculated by formula (6).

$$
C D A P=\frac{100 \times(P E C-P G P)}{P E C}
$$

In which, PEC is the pixel numbers of entire crown profile and the PGP is the pixel numbers of green part.

To make a comparison with the CDAP, the inflection point (IP) of crown discoloration was calculated in the procedure of threshold responsive analysis. Each crown image was divided into ten sections with equal width from leeward to windward of the crown. Having been repeatedly regression tested, the Relative G/L (RGL) for crown sections gradually decreases from leeward to windward and can be modeled by logistic threshold responsive function (refer to formula 7) for the asymmetrically discolored crowns.

$$
R G L(n)=\frac{k}{1+e^{a-r n}}
$$

Where, RGL (refer to formula 8) stands for relative $\mathrm{G} / \mathrm{L}$ and $n(n=1,2 \ldots 10)$ is ordinal section number from leeward to windward of the crown. $\operatorname{RGL}(n)$ is the RGL value at $\mathrm{n}$ section. Obtained by regression process, $a$ is a constant, $r$ is a coefficient and $k$ presents the maximum value that RGL value can reach. Based on the mathematic principle, the IP of formula (7) will exist only when the secondary differential value equals to $0(n=a / r)$, and the $\frac{d^{2} R G L}{d n}>0$ when $n<a / r$ and $\frac{d^{2} R G L}{d n}<0$ when $n>a / r$. Checked by secondary differential values at the point $n>a / r$ and $n<a / r$, all IP values existed and were mathematically meaningful except the IP for samples with the crown of overall green or entirely brown. During the measurement, the IP values for crowns of overall green were numbered with the maximum value of 10 and for the crowns of overall brown with the minimum value of 0 in order to digitalize all of the data. The IP can be considered as the estimation value of the threshold between green part and non-green part of discolored crowns and as a reference for the CDAP.

$$
R G L_{i}=\frac{100 \times\left(G / L_{i}-G / L_{\min }\right)}{\left(G / L_{\max }-G / L_{\min }\right)}
$$

Where, $\mathrm{G} / \mathrm{L}_{i}$ is the $\mathrm{G} / \mathrm{L}$ value for $i$ section $(i=$ $1,2,3 \ldots 10), G / L_{\min }$ is the minimum $\mathrm{G} / \mathrm{L}$ value of all sections in all sampled crowns and $\mathrm{G} / \mathrm{L}_{\max }$ is the maximum $\mathrm{G} / \mathrm{L}$ value in all sections of all sampled crowns.

To study the variation of leaf necrosis among different sites with different distance from coastline, six standard branches, three each from windward and leeward, were respectively sampled from the sites near the Yamaguchi Bay, near the Fushino River and in the Anno Canyon, which were 1.7, 12.6 and $40.1 \mathrm{~km}$ away from the coastline separately (refer to Fig. 1). All of the leaves on the branches were also visually divided and counted into five necrotic scales of nil, slight, middle, serious and dead. The distance from coastline (DC) was defined as the shortest distance from tree sites to the coastline and measured with an electronic atlas named Atlas Z Proffessional5. The DC of Yamaguchi University, the image analysis was engaged in, is $12.6 \mathrm{~km}$ from the coastline. The SPAD values of individual leaves were the average value of 30 duplications per leaf impartially measured by using a SPAD-502 chlorophyll meter.

\section{Results and Analysis}

\subsection{Characteristics of leaf necrosis induced by Typhoon 0613}

Struck by Typhoon 0613, leaf necrotic symptoms appeared on many ginkgo trees and the striking variance in necrosis was found during the post anticyclone weather environment (refer to Fig. 2, leaves). Even leaves on the same crown displayed different necrotic symptoms. On slightly damaged leaves, only tip and/or marginal necrosis was observed, whereas more seriously damaged leaves showed enlarged necrotic areas on them, even only the proximal part remained green. The most serious symptoms of leaf necrosis certainly were the entirely brown or red/brown leaves.

It was observed that most of the sampled braches from leeward of ginkgo tree crowns were composed

Table 1 Percentage of necrotic leaves on windward and leeward of ginkgo crown

\begin{tabular}{lccccc}
\hline & Nil necrosis (\%) & Slight necrosis (\%) & Middle necrosis (\%) & Serious necrosis (\%) & Dead leaves (\%) \\
\hline Leeward & 71 & 25 & 4 & 0 & 0 \\
Windward & 8 & 22 & 27 & 26 & 17 \\
\hline
\end{tabular}


of non-necrotic and slightly necrotic leaves by visual estimation. Most of leaves on branches sampled from windward of the crowns were partially necrotic leaves and dead leaves (refer to Table 1). Therefore, many crowns of damaged ginkgo trees can be clearly divided into green part and non-green part. This suggested it was the difference of necrotic leaves that made the crown of damaged ginkgo trees appear asymmetrically discolored (refer to Fig. 2, crown).

\subsection{Leaf necrosis estimated by LNAP and $G / L_{\text {leaf }}$ value}

By sampling and visual method above mentioned, only qualitative scale results can be obtained. As an index of necrotic extent of individual leaves, the LNAP was determined as the criterion of the damage. It can be measured by many methods such as check counter, leaf area meter, photo image pixel method etc. In this study, the image pixel method was used to determine the LNAP for its high accuracy and low variance (Chen et al. 2006, Bai et al. 2005). The image pixel analysis method used in leaf area measurement can be remarked as a fine check counter, in which each image pixel can be considered as a check with 5,022 checks per square centimeter for 180 dpi images. However, using visual method is difficult to estimate the exact account of leaf area as the image pixel analysis, especially for variously necrotic leaves and asymmetric discolored crowns.

The total leaf necrotic area and total leaf area were estimated by using the LNAP and mean leaf area on the basis of same necrotic scales as that in Table 1 (refer to Table 2). It also manifested the fact that most leaves on leeward of the sampled crowns were composed of nil and slightly necrotic leaves and most leaves on windward of the sampled crowns were partially necrotic and dead leaves. The total necrotic leaf area of the windward of damaged crowns was more than that of the leeward with the windward and leeward ratio (W/Le) equaling to 7.416. By comparison, the total leaf area showed an inverse tendency with the

Table 2 Total necrotic leaf area and total leaf area per branch

\begin{tabular}{|c|c|c|c|c|c|c|c|c|c|}
\hline & & $\begin{array}{c}\text { Nil } \\
\text { necrosis } \\
\left(\mathrm{mm}^{2}\right)\end{array}$ & $\begin{array}{c}\text { Slight } \\
\text { necrosis } \\
\left(\mathrm{mm}^{2}\right)\end{array}$ & $\begin{array}{c}\text { Middle } \\
\text { necrosis } \\
\left(\mathrm{mm}^{2}\right)\end{array}$ & $\begin{array}{c}\text { Serious } \\
\text { necrosis } \\
\left(\mathrm{mm}^{2}\right)\end{array}$ & $\begin{array}{c}\text { Dead } \\
\text { leaves } \\
\left(\mathrm{mm}^{2}\right)\end{array}$ & $\begin{array}{c}\text { Total } \\
\left(\mathrm{mm}^{2}\right)\end{array}$ & $\begin{array}{c}\text { Leaf } \\
\text { number }\end{array}$ & $\mathrm{W} / \mathrm{Le}^{\dagger}$ \\
\hline Necrotic & Leeward & 0 & 6349 & 4039 & 2156 & 0 & 12545 & 152 & \multirow{2}{*}{7.416} \\
\hline Area & Windward & 0 & 5977 & 15178 & 12850 & 59025 & 93032 & 100 & \\
\hline Total & Leeward & 243972 & 100736 & 11805 & 3148 & 0 & 359662 & 152 & \multirow{2}{*}{0.659} \\
\hline Area & Windward & 43285 & 69256 & 41711 & 23610 & 59025 & 236889 & 100 & \\
\hline
\end{tabular}

Where W/Le is the ratio between windward and leeward. The data comes from average of three sampled branches.

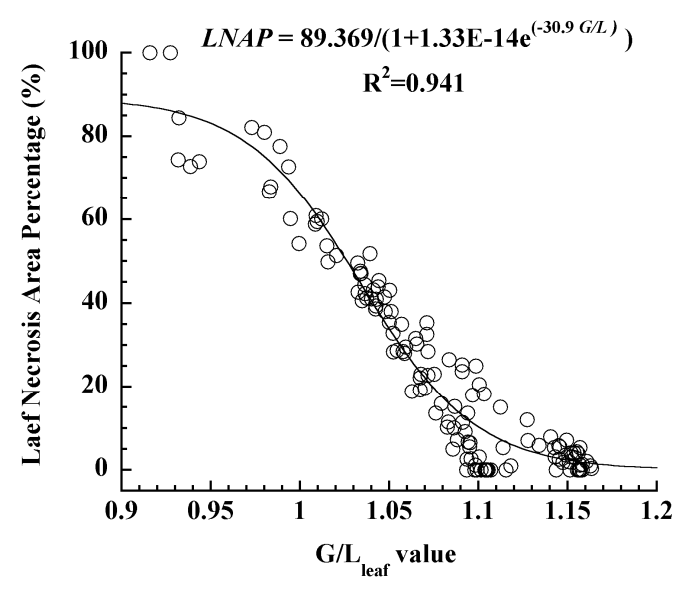

Fig. 4 Relation between Leaf Necrosis Area Percentage (LNAP) and G/L $\mathrm{L}_{\text {leaf }}$ value of ginkgo. An inverse logistic function was obtained.

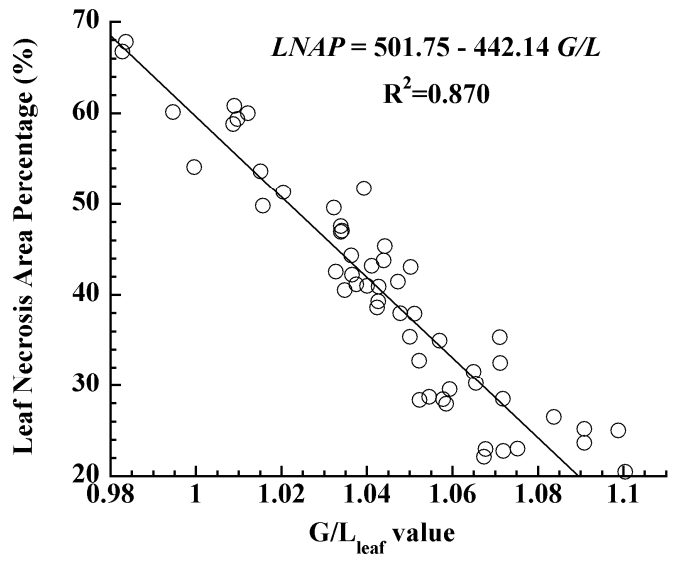

Fig. 5 Relation between Leaf Necrotic Area Percentage (LNAP) and $\mathrm{G} / \mathrm{L}_{\text {leaf }}$ value of ginkgo after remove the leaf samples with LNAP $<20 \%$ and $>$ $70 \%$. A linear equation was obtained. 


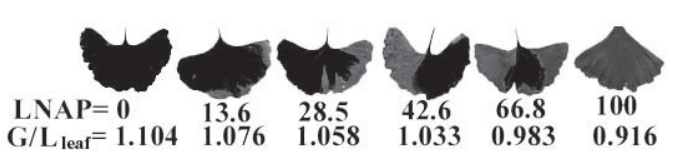

Fig. 6 Model leaf samples and the corresponding Leaf Necrotic Area Percentage (LNAP) and G/L $\mathrm{L}_{\text {leaf }}$ value.

W/Le equaling to 0.659 . It implies that after hit by Typhoon 0613, not only leaf necrosis and asymmetric crown discoloration occurred, but also the defoliation as well as asymmetric growth took place.

An inverse logistic function between the $\mathrm{G} / \mathrm{L}_{\text {leaf }}$ value and LNAP for ginkgo leaves was obtained by regression analysis, with $\mathrm{R}^{2}=0.941$ (refer to Fig. 4). It indicated that as the LNAP increased the $\mathrm{G} / \mathrm{L}_{\text {leaf }}$ value decreased gradually with a nonlinear pattern. After removing the leaf samples with LNAP $<20 \%$ and $>70 \%$, the relation equation changed to a linear function, with $\mathrm{R}^{2}=0.870$ (refer to Fig. 5).

The leaves with LNAP $<20 \%$ or $>70 \%$ showed variation in leaf color. By measuring the SPAD value of the non-necrotic part of leaves, it also appeared significant difference among sampled branches $(\mathrm{P}=$ $\left.2.3637 \times 10^{-12}, F=30.735^{* *}\right)$. It suggested that the $\mathrm{G} / \mathrm{L}_{\text {leaf }}$ was affected by the difference of leaf colors in these ranges. In the range of LNAP $>20 \%$ and $<70 \%$, the $\mathrm{G} / \mathrm{L}_{\text {leaf }}$ value was even much sensitive to the variance of leaf necrotic area than the leaf color difference, according to the near linear relationship. From this perspective, the $\mathrm{G} / \mathrm{L}_{\text {leaf }}$ value of RGB image responds to both chlorosis and necrosis of necrotic leaves. In fact, ginkgo leaves on different crowns showed not only different leaf necrosis but also leaf color variance (chlorosis). Therefore, it has potential to be used in estimating the damaged status of crowns damaged by typhoons like Typhoon 0613. It also indicated that the leaves with similar color status should be selected to estimate the necrotic area based on $\mathrm{G} / \mathrm{L}_{\text {leaf }}$ value. Figure 6 gives some model leaves estimated by LNAP and corresponding $\mathrm{G} / \mathrm{L}_{\text {leaf }}$ values.

\subsection{Asymmetric crown discoloration estimated by CDAP, IP and $G / L_{\text {crown }}$ values}

Compared between the leaves and crowns of ginkgo trees hit by Typhoon 0613, almost similar characteristics has been found, which showed partial area of them became brown or red brown. Therefore, as the LNAP was used as the discriminatory standard for leaf necrosis, the CDAP and IP were used to evaluate the asymmetric crown discoloration.

Both CDAP and IP can be used to reflect the proportion of the green part to entire crown. However, the former was subjectively divided green part and non-green part by visual method and the later was objectively calculated by parameters from the logistic threshold responsive function. Because of the big contrast between the green part and non-green part of the ginkgo trees injured by Typhoon 0613, the two indices are consistent with each other with the square correlative coefficient equaling to 0.811 (refer to Fig. 7).

In comparison to the individual leaves, the crown of trees manifested characteristics of more complex structure, such as leaf orientation variance and difference in gap fraction and light condition. Although it hampered the image taking and RGB image analysis, a significant inverse linear relation between $\mathrm{G} / \mathrm{L}_{\text {crown }}$ value and CDAP for sampled ginkgo crowns was obtained, with $\mathrm{R}^{2}=0.826$ (refer to Fig. 8a). Almost a same level of positive linear relation between $G / L_{\text {crown }}$ value and IP for the sampled ginkgo crowns was also acquired, with $\mathrm{R}^{2}=0.827$ (refer to Fig. 8 b)

Therefore, it suggested that not only leaf necrosis but also asymmetric crown discoloration, induced by strong typhoons like Typhoon 0613, can be quantitatively estimated by $\mathrm{G} / \mathrm{L}$ values. Some model crowns (Fig. 9a, b, c, d and e) estimated by $\mathrm{G} / \mathrm{L}_{\text {crown }}$ values, CDAP and IP were shown in Fig. 9. By comparison, the commonly used visual scale method usually scales the crown healthy status like VS index in the figure. In

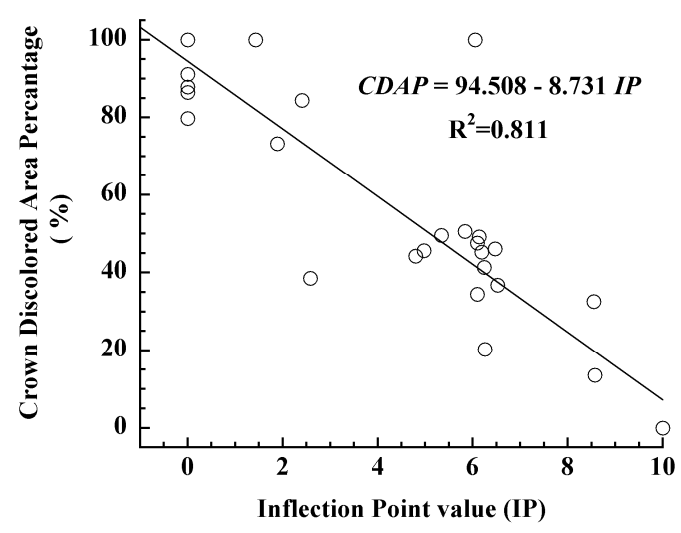

Fig. 7 The relationship between Inflection Point (IP) and Crown Discolored Area Percentage (CDAP), an inverse linear function was showed in the figure. 

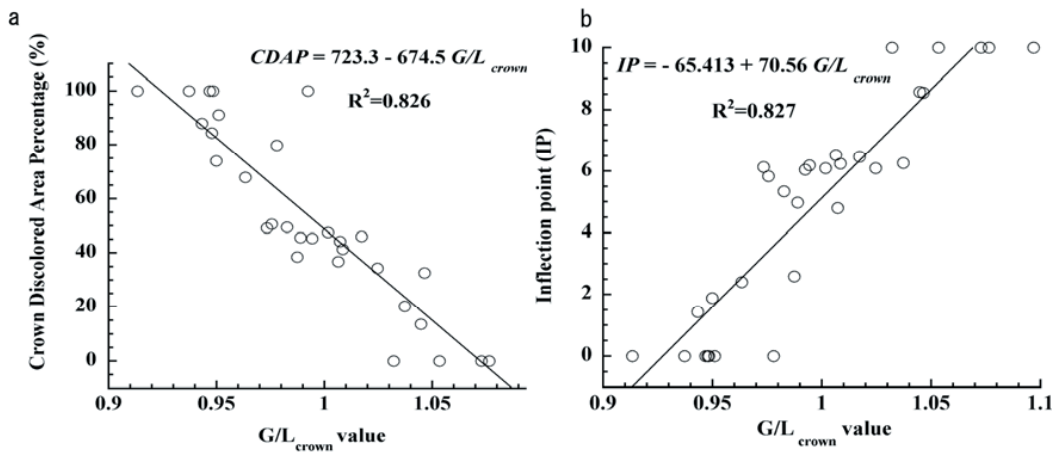

Fig. 8 A inverse relationship between Crown Discolored Area Percentage (CDAP) and G/ $\mathrm{L}_{\text {crown }}$ value of ginkgo, and a positive function between Inflection point (IP) and $\mathrm{G} / \mathrm{L}_{\text {crown }}$ value of ginkgo were presented in $8 \mathrm{a}$ and $8 \mathrm{~b}$ respectively.

a

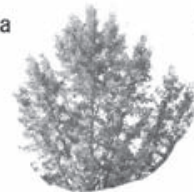

G/L crown

IP

CDAP

VS

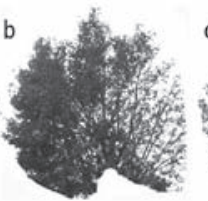

1. 037

6. 26

20. 26

| |

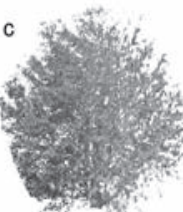

0. 989

4. 98

45. 64

I I I

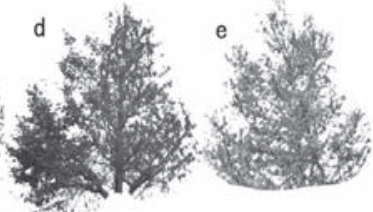

0.963

2. 587

84. 391

IV
0. 937

0

100

V
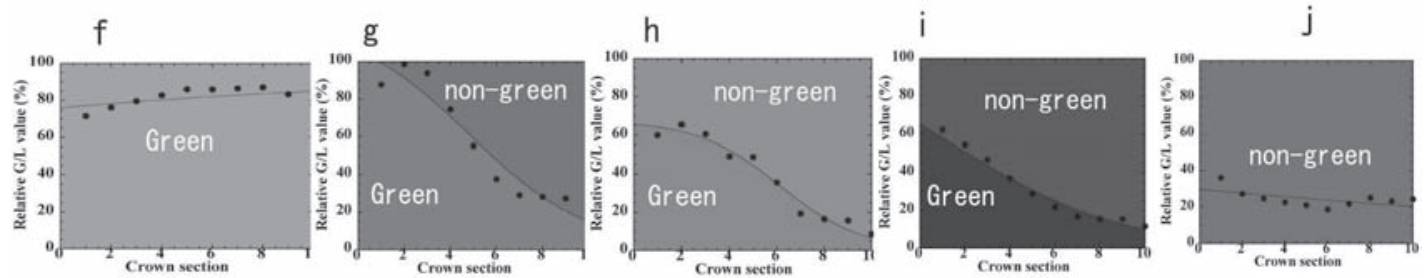

Fig. 9 From 9a to 9e were five model crowns corresponded by $\mathrm{G} / \mathrm{L}_{\text {crown }}$, Crown Discolored Area Percentage (CDAP) and inflection point (IP) of regression curve and respectively belong to five visual scales (VS). From 9f to $9 j$ were five figures of threshold responsive function of relative $G / L_{\text {crown }}(R G L)$ and showed different logistic curves, which divide the crown into green part and non-green. The $9 \mathrm{f}$ and $9 \mathrm{j}$ presented entire green and overall brown respectively and their IP was more than 10 and less than 0 separately.

From 9f to $9 \mathrm{j}$, the vertical coordinate is RGL value and horizontal coordinate is crown section orders from leeward to windward.

Fig. 9, they were also shown by five figures of threshold responsive function. The logistic curve divided the asymmetrically discolored crowns into green and non-green parts (refer to Fig. 9g, h, i). The crown discoloration of injured crowns was clearly described. It indicated that the crown injured by Typhoon 0613 was more serious on windward than on leeward. It showed responsive equations of level line for the crowns with characteristics of overall green and entirely brown (refer to Fig. 9f, j) and respectively located on top and bottom of the coordinate. It suggested that the threshold responsive analysis also has a potential to estimate the healthy status of ginkgo trees injured by Typhoon 0613.

\subsection{Relation between DC and both $G / R_{\text {crown }}$ and $G / L_{\text {crown }}$ values of ginkgo}

It was reported that the damage to ginkgo trees by strong typhoons appeared inverse relation to the distance from coastline (Okinaka et al., 1984). Corresponding to the previous research result, the damage to 
Table 3 Percentage of necrotic leaves from different ginkgo trees in different sites

\begin{tabular}{lccccc}
\hline \multicolumn{1}{c}{ Sites } & $\begin{array}{c}\text { Nil } \\
\text { necrosis (\%) }\end{array}$ & $\begin{array}{c}\text { Slight } \\
\text { necrosis (\%) }\end{array}$ & $\begin{array}{c}\text { Middle } \\
\text { necrosis (\%) }\end{array}$ & $\begin{array}{c}\text { Serious } \\
\text { necrosis (\%) }\end{array}$ & $\begin{array}{c}\text { Dead } \\
\text { leaves (\%) }\end{array}$ \\
\hline In Anno Canyon & 94 & 6 & 0 & 0 & 0 \\
Near Fushino River & 39 & 24 & 16 & 13 & 8 \\
Near Yamaguchi Bay & 2 & 19 & 18 & 13 & 48 \\
\hline
\end{tabular}
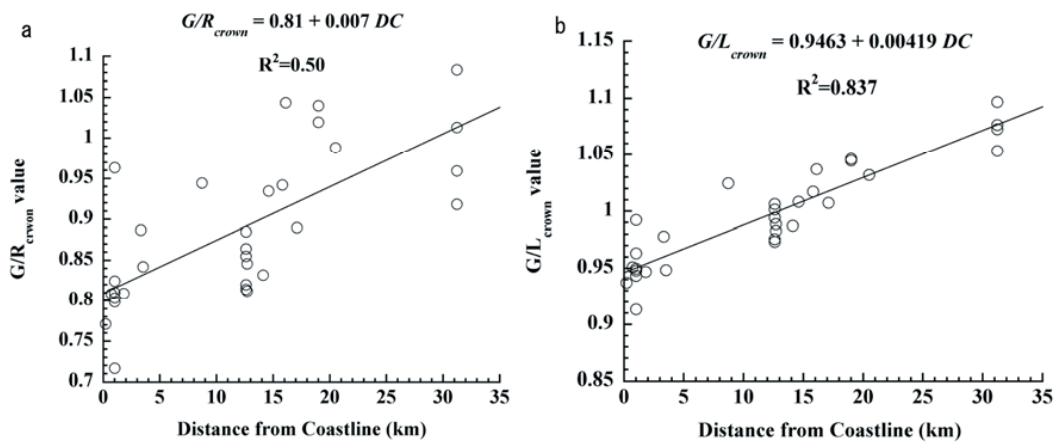

Fig. 10 Relation between Distance from Coastline (DC) and $G / R_{\text {crown }}$ value of ginkgo calculated with 31 samples (10a), and Relation between Distance from Coastline (DC) and $\mathrm{G} / \mathrm{L}_{\text {crown }}$ of ginkgo calculated with same samples (10b). By comparison, the deviation of the $G / R_{\text {crown }}$ was clearly larger than that of the $G / L_{\text {crown. }}$.

ginkgo trees by strong Typhoon 0613 also appeared an inverse relation to the distance from coastline according to the result of RGB image analysis. A similar result had been obtained in the study at different sites with different distance from coastline with sampling method in Table 3. It showed almost all the leaves sampled from ginkgo crowns in the site in Anno Canyon, more than $40 \mathrm{~km}$ far from the coastline, were mainly composed with non-necrotic leaves. By contrast, the most leaves sampled from the site near the Yamaguchi Bay, less than $2 \mathrm{~km}$ to the coastline were seriously necrotic leaves and dead leaves. The leaf samples from the site near the Fushino River, about $13 \mathrm{~km}$ from coastline, were at middle position. It also indicated that the difference of the percentage of necrotic leaves made the damaged ginkgo trees appeared different asymmetric crown discoloration for the different sites with different distance from the coastline.

By comparison, both $\mathrm{G} / \mathrm{R}_{\text {crown }}$ and $\mathrm{G} / \mathrm{L}_{\text {crown }}$ measured by image pixel method appeared positive relation to the distance from coastline with $\mathrm{R}^{2}=0.50$ and $\mathrm{R}^{2}=0.837$ for $\mathrm{G} / \mathrm{R}_{\text {crown }}$ and $\mathrm{G} / \mathrm{L}_{\text {crown }}$ separately (refer to Fig. $10 \mathrm{a}, \mathrm{b}$ ). Howerever, the deviation of $G / R_{\text {crown }}$ values was 2.02 times more than that of $\mathrm{G} / \mathrm{L}_{\text {crown }}$ values. It may be the cause of the lower relation between $\mathrm{G} / \mathrm{R}$ value and $\mathrm{DC}$ than that between $\mathrm{G} / \mathrm{L}$ value and DC. It suggested that the $\mathrm{G} / \mathrm{L}_{\text {crown }}$ was more appropriate to be used analyzed the images taken under the conditions with big lightning difference. Both results from visual scale estimation and image analysis showed that the farther is from the coastline, the less damage to ginkgo trees and the larger the $\mathrm{G} / \mathrm{L}_{\text {crown }}$ value. In other word, the nearer is to the coastline, the more is the leaf necrosis and asymmetric crown discoloration for ginkgo trees, and the more serious damage to ginkgo trees.

\section{Conclusion and Discussion}

The commonly used method of measuring ginkgo tree crowns damaged by typhoons is visual estimation, although it is usually affected by subjective judgement with various results from different observers. Labor requirement and time consumption rendered the sampling method unable to be used in studying trees in a large area by fewer researchers. In the study, it reveals only the qualitative scale results can be obtained and limits its use in the field studies, especially for landscape tree species.

Research about asymmetric crown discoloration has been seldom found recently, especially on measuring the asymmetric discolored crown by RGB image analysis. Comparing to the conventional method, the RGB image analysis can be used to measure the characters of trees quantitatively with characteristics of less labor, less time needs and low cost. The possibility 
of storage and reusing for digital images made the continuing research possible.

During the study of Typhoon 0613, the relation between the $\mathrm{G} / \mathrm{L}_{\text {leaf }}$ value and LNAP of ginkgo leaves indicate that not only chlorosis but also necrosis can be quantitatively estimated by using the $\mathrm{G} / \mathrm{L}$ value of RGB image. Although, the hue of leaf and crown images were affected by different light condition, a significant relation between $\mathrm{G} / \mathrm{L}_{\text {crown }}$ and CDAP or IP had been obtained since the great contrast of green part and the non-green part of the ginkgo crowns hit by Typhoon 0613. It may be an alternative tool to estimate the leaf necrosis status and asymmetric crown discoloration induced by typhoons like Typhoon 0613 .

Field trees are affected by many environmental factors. The response from the trees to these factors can be divided into different categories. Only extreme limit factor can induce trees into necrotic status. Salisbury had noted in 1805 that great leaf injury occurred when rain was not associated with strong wind. It is no surprise that leaf necrosis of ginkgo trees occurred for the reason of extremely strong wind with less rain and persistent no rain after the typhoon's hit, which is rarely extreme event for more than 40 years in Yamaguchi.

It was the variation of necrotic leaves that made the crown of damaged ginkgo trees appeared asymmetrically discolored. The logistic function from threshold responsive analysis indicated that more serious injury occurred on the windward of the asymmetric discolored crowns. The proper relationship between IP and CDAP suggested that as an objectively measured parameter the IP has potential to describe the asymmetric discoloration characters of ginkgo trees hit by typhoons like Typhoon 0613. As an index of the image hue of entire crown, the $\mathrm{G} / \mathrm{L}_{\text {crown }}$ value also has a potential to be used to estimate the color change of overall crown originated from leaf necrosis or asymmetric crown discolorations.

\section{Acknowledgements}

This study was performed at the Research Laboratory of Environmental Ecology, Faulty of Agriculture, Yamaguchi University. We would like to express our gratitude to all members who help our works in image analysis.

The study benefits from the resources of landscape trees in Yamaguchi City, especially the ginkgo that is the symbol tree of Yamaguchi City. We would also like to express our thanks to all members who engaged in planting, managing and maintaining the ginkgo trees.

\section{Reference}

Adamsen, F.J., Pinter, P.J., Barnes, Jr. E. M, Lamorte, R. L., Wall, G.W., Leavitt, S.W., and Kimball, B.A., 1999: Measuring wheat senescence with a digital camera. Crop Sci., 39, 719-724.

Bai, J.H., Wang, K., CHU, Z. D., Chen, B., and Li, Sh. K., 2005: Comparative Study on the Measure Methods of the Leaf Area. J. Shihezi Univ. (Nat. Sci.), 23, 216-218 (In Chinese).

Bréda, N.J.J., 2003: Ground-based measurements of leaf area index: a review of methods, instruments and current controversies, J. Exp. Bot., 54, 2403-2417.

Cai, H.C., Cui, H., Song, W.T., and Gao, L.H., 2006: Preliminary study on photosynthetic pigment content and color feature of cucumber initial blooms. Tran. CSAE, 22(9), 34-38 (In Chinese).

Chen, S.L., Wu, Zh.H., and Ma, S.J., 2006: Measuring Methods of Eucalypt Leaf Area with Digital Image Processing Technology. Eucalypt. Sci. Tec., 23(1), 6-10 (In Chinese).

Durbin, R.D., 1978: Abiotic diseases induced by unfavorable water relations. In Water deficits and plant growth volume 5, (ed. by Kozlowski T. T.). Academic Press, New York, 101-107.

Geneve, R.L., and Kester, S.T., 2001: Evaluation of seedling size following germination using computeraided analysis of digital image from flat bed scanner. Hortsci., 36, 1117-1120.

Günthardt-Goerg, M.S., and Vollenweider, P., 2007: Linking stress with macroscopic and microscopic leaf response in trees, New diagnostic perspectives. Environ. Pollut., 147, 467-488.

Iwaya, K. and Yamamoto, H., 2005: The Diagnosis of Optimal Harvesting Time of Rice Using Digital Imageing. J. Agric. Meteorol., 60, 981-984 (In Japanese).

Karcher, D.E. and Richardson, M.D., 2003: Quantifying Turfgrass Color Using Digital Image Analysis. Crop Sci., 43, 943-951.

Kawashima, S. and Nakatani, M., 1998: An algorithm for Estimating Chlorophyll Content in Leaves Using a Video Camera. Ann. Bot., 81, 49-54.

Maki, T., Suzuki, Y., Kamoda, F., Hayakawa, S. and Tomari, K., 1991: Meteorological disaster in agriculture and the countermeasures. Yokendo, pp. 345 
(In Japanese).

Mizoue N., and Masutani T., 2003: Image analysis measure of crown condition, foliage biomass and stem growth relationships of Chamaecyparis obtuse. Forest Ecol. Manage., 172, 79-88.

Nobel, P.S., 1981: Wind as an ecological factor. In Encyclopedia of Plant Physiology New Series Volume 12A-Physiological Plant Ecology I, (ed. by Lange, O. L. L., Nobel, P. S., Osmond, C.B., and Ziegler, H.), Springer-Verlag, Berlin, Heidelberg, 475-500.

Okado, M. and Nakamura, Y. 1993: Studies on the Measurement of the Color of Rice Leaves by Image Processing, J. Jpn. Soc. Agr. Machinery, 55(5), 75-81 (In Japanese).

Okinaka, T., Masuda, S. and Sugahara, M., 1984: The Salty Wind Damage on landscape trees by Typhoon No. 8218. Tech. Bull. Fac. Hort. Chiba Univ., 34, 91-97 (In Japanese).

Okinaka, T., Sugahara M. and Kobayashi, T., 1990: Wind tunnel experiments on the effect of wind blow and adhering salt in salty wind damage on landscape trees. Tech. Bull. Fac. Hort. Chiba Univ., 43, 121-128 (In Japanese).

Purcell, L.C., 2000: Soybean canopy coverage and light interception measurement using digital imagery. Crop Sci., 40, 834-837.

Richardson, M. D., Karcher, D. E. and Purcell, L. C., 2001: Quantifying Turfgrass Cover Using Digital Image Analysis. Crop Sci., 41, 1884-1888.

Rogers,P., 2002: Using Forest Health Monitoring to assess aspen forest cover change in the southern Rockies ecoregion. Forest Eco. Manage., 155, 223-236.

Salisbury, R., 1805: An account of a storm of salt, Linn. Soc. Landon Trans., 8, 286-290.

Santamour, F. S., Jr., He, Shan-an, and McArdle, A. J., 1983: Checklist of Cultivated Ginkgo. J. Arbori- culture, 9, 88-92.

Shimizu, Y., 2004: Selection of proper landscape tree for costal region (I) - the region salt wind damage easily occur and the distance from coastline. Quart. Hokkaido Fore. Res. Inst., 134, 16-20 (In Japanese).

Skaloudova, B., Krivan, V., and Zemek, R., 2006: Computer-assisted estimation of leaf damage caused by spider mites. Comput. Electron. Agr., 53, 81-91.

Solberg, S., 1999: Crown density assessments, control surveys and reproducibility, Environ. Monit. Assess., 56, 75-86.

Suzuki T., 1995: Measurement of growth of plug seedlings by image processing in broccoli. Acta Horti., 399, 333-343.

Suzuki, T., Murase, H., and Honami,N., 1999: Non-destructive Growth Measurement Cabbage Pug seedlings Population by Image Information, J. Jpn. Soc. Agr. Machinery, 61(2), 45-51 (In Japanese).

Takahashi H. and Tani, H., 1981: Study on the interaction between wind and trees in an Urban Area. $J$. Agric. Meteorol., 37, 239-243 (In Japanese).

Tian, W., and Jing, X., 2006: Investigation, analysis and countermeasure for leaf chlorosis and necrosis of street ginkgo tree in Shenyang of China. J. Hort. Sci. Tec., 99, 16-24 (In Chinese).

Treshow, T., 1970: Environment and plant response. Mcgraw-Hill, New York, pp.442.

Vollenweider, P. and Günthardt-Goerg, M.S., 2006: Erratum to "Diagnosis of abiotic and biotic stress factors using the visible symptoms in foliage", Environ. Pollut., 140, 562-571.

Yamamoto R., 1979: Protection of fruit tree against the wind damages. J. Agric. Meteorol., 35, 177-187 (In Japanese). 